\title{
Initiation of pharmacist-psychiatrist collaborative patient education in ambulatory care settings of a tertiary care teaching hospital in south India
}

\author{
Sai Krishna Gudi ${ }^{1}$, Ambed Mishra ${ }^{1}$, Tony David Kurian ${ }^{1}$, Sravani Alla ${ }^{1}$, Justin Kurian ${ }^{1}$, Madhan Ramesh ${ }^{1 *}$, Kishor Manohar Rao ${ }^{2}$ \\ 'Department of Pharmacy Practice, JSS College of Pharmacy, JSS Academy of Higher Education Research, Mysore, India. \\ ${ }^{2}$ Department of Psychiatry, JSS Medical College, JSS Academy of Higher Education Research, Mysore, India..
}

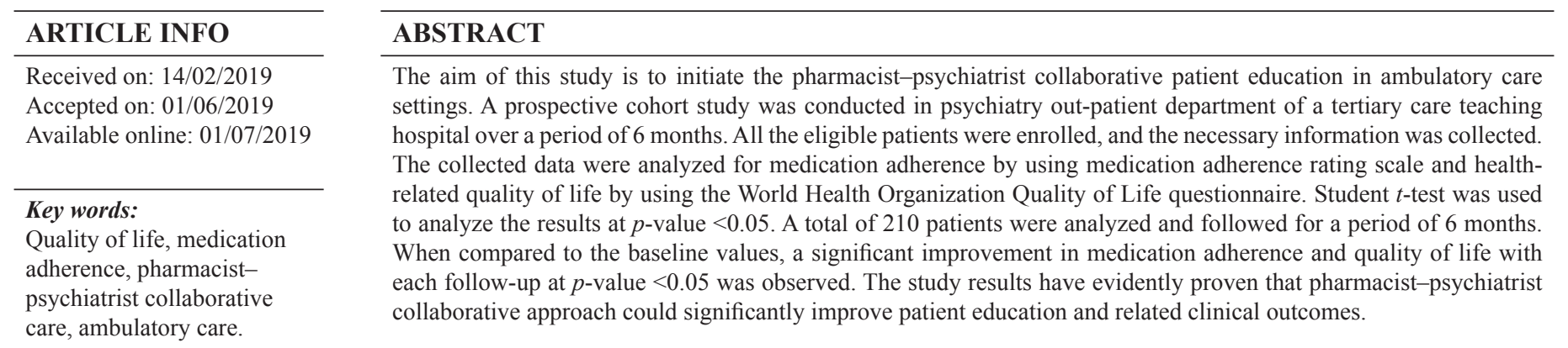

\section{INTRODUCTION}

Mental health disorders imitate a leading public health concern and cause high levels of disability and generally unrecognized and untreated as well (Mishra et al., 2017a). At some point in time in life, behavioral and mental disorders commence in $10 \%$ of the adult population, and it contributes more than $12 \%$ of global disease burden (Ormel et al., 2008). Among high-, middle-, and low-income countries, despite of being responsible for a high level of disability, mental health disorders are often not identified and under-treated. People who are on psychotropic medications for mental health disorders are at higher risk of developing medication-related problems, such as adverse drug reactions. Treatment discontinuation and medication non-adherence are the significant challenges faced by mental health care professionals

\footnotetext{
${ }^{*}$ Corresponding Author

M. Ramesh, Department of Pharmacy Practice, JSS College of Pharmacy, JSS Academy of Higher Education Research, Mysore, India.

E-mail:mramesh@jssuni.edu.in
}

while treating their patients. Educating the patient helps eliminate such non-adherence and treatment discontinuations. An informed and educated patient can participate in his/her own treatment plan, improve medication adherence, as well as helping to reduce the errors associated with medication use (Phokeo et al., 2004). In the developing countries like India, catering of drug information during the time of dispensing to individuals with mental disease is minimum (Thakkar et al., 2013). Lack of knowledge of dispensing pharmacist about the psychotropic medication, busy working schedule, and lack of suggestion from the psychiatrists are considered as the possible reasons for this (Chisholm-Burns et al., 2010; Stoner et al., 2010).

Pharmacist-Physician collaborative care approach is a recent concept in countries like India. Although the clinical pharmacy services were initiated in India two decades ago, the involvement of a clinical pharmacist in mental health care is minimal (Happell et al., 2004). Most of the clinical pharmacy services are focused on inpatient settings. The patients visiting the outpatient departments of Indian hospitals are not able to obtain the pharmaceutical care services due to non-availability of the competent pharmacist at the outpatient settings of each department 
(Mishra et al., 2017b). Also, the number of medications prescribed to each patient to treat multiple ailments, and the information given to them on the proper use of these medications is minimal due to the increased workload of healthcare professionals at the outpatient departments (Kucukarslan et al., 2011). As a result, this study was conducted to initiate the Pharmacist-Psychiatrist collaborative patient care in an ambulatory care setting.

\section{MATERIALS AND METHODS}

A prospective cohort study was conducted in an outpatient department of Psychiatry at the JSS Hospitals, Mysuru, Karnataka over a period of 6 months, i.e., November-2015 to April-2016. Literate patients who visited the psychiatry out-patient department with either sex aged $\geq 18$ years and who were treated for Schizophrenia, Depression, Bipolar Affective Disorder, and Alcohol Dependence Syndrome were included in the study. Patients who were non-cooperative and those treated in ambulatory care setting of other departments were excluded from the study. The study was commenced after obtaining the approval from Institutional Human Ethics Committee of JSS College of Pharmacy, Mysuru, India.

Patients who satisfied the study's inclusion criteria were included in the study in consultation with a Psychiatrist after obtaining the informed consent from the patients. Medication adherence was assessed by using Medication Adherence Rating Scale (MARS) questionnaire (Thompson et al., 2000) which consists of 10 questions and quality of life by using the World Health Organization Quality Of Life- brief (WHOQOL-BREF) questionnaire (The WHOQOL Group, 1998). WHOQOL-BREF questionnaire consists of 26 questions categorized under four different domains, i.e., physical health, psychological health, social relationships, and environmental quality of life at the baseline. Patient education was provided to the patients by the Pharmacist and the Psychiatrist as well. The subjects were followed during two follow-ups, and medication adherence and quality of life was assessed during each follow-up. Eventually, the obtained results were analyzed and compared from baseline to first, and second follow-ups (Fig. 1).

The data which were normally distributed were crosschecked for accuracy by entering them into the Microsoft Excel Spreadsheet. Then, the data were imported to SPSS version 11.0 for further analysis. Descriptive statistics, such as means, standard deviations, and frequency distributions, were computed on sample characteristics. Student $t$-test was used to calculate the differences between the means at $p$-values $<0.05$.

\section{RESULTS}

A total of 218 patients with psychiatric disorders were enrolled into the study; out of whom, 210 patients completed the study, with a lost in follow-up of eight patients. Of 210 patients, the majority of the patients were males $(53.33 \%)$. Majority of the study participants were belonging to $18-39$ years $(52.85 \%)$, followed by $40-59$ years $(41.42 \%)$, and $\geq$ andyears $(5.71 \%)$ age groups, respectively. Demographic information of the study population are depicted in Table 1 .

\section{Assessment of Medication Adherence using MARS Scale}

Assessment of patients' medication adherence from the baseline to first follow-up, first follow-up to second follow-up, and baseline to second follow-up have manifested a mean increase of
$0.94 \pm 0.06,0.99 \pm 0.16$, and $1.93 \pm 0.22$, respectively. Further details on the medication adherence of the study population are depicted in Table 2.

\section{Assessment of health-related quality of life using WHOQOL-BREF scale}

Assessment of patients' health-related quality of life from the baseline to first follow-up, first follow-up to second follow-up, and baseline to second follow-up have manifested a mean increase of $16.1 \pm 2.68,10.76 \pm 0.44$, and $26.86 \pm 3.12$, respectively. Further details on the quality of life of the study population are represented in Table 3 .

\section{DISCUSSION}

The ultimate goal of any healthcare professional in treating a patient is to deliver quality healthcare in order to

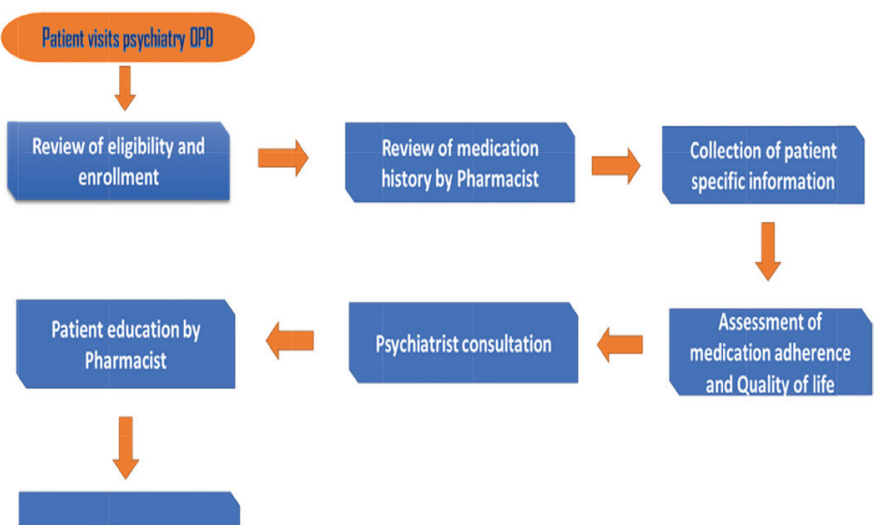

Figure 1. Pharmacist-psychiatrist collaborative model.

Table 1. Demographic details of the study population at JSS Hospital, Mysore, India in 2016.

\begin{tabular}{llcc}
\hline Demographics & Category & $\begin{array}{c}\text { No. of subjects } \\
(\boldsymbol{N}=\mathbf{2 1 0})\end{array}$ & Percentage (\%) \\
\hline \multirow{3}{*}{ Age } & $18-39$ & 111 & $52.85 \%$ \\
& $40-59$ & 87 & $41.42 \%$ \\
\multirow{2}{*}{ Gender } & $\geq 60$ & 12 & $5.71 \%$ \\
& Male & 112 & $53.33 \%$ \\
\multirow{3}{*}{ Marital status } & Female & 98 & $46.66 \%$ \\
& Single & 56 & $26.66 \%$ \\
& Married & 150 & $71.42 \%$ \\
& Separated & 4 & $1.90 \%$ \\
\hline
\end{tabular}

Table 2. Medication adherence scores using Medical Adherence Rating Scale at JSS Hospital, Mysore, India in 2016.

\begin{tabular}{lccc}
\hline & Follow up's & $\begin{array}{c}\text { MARS score } \\
(\text { Mean } \pm \text { S.D })\end{array}$ & $\begin{array}{c}\text { p-value* } \\
(<0.05)\end{array}$ \\
\cline { 2 - 4 } $\begin{array}{l}\text { Mars scale } \\
\text { (medication }\end{array}$ & Baseline & $5.31 \pm 0.61$ & $0.045^{* *}$ \\
adherence) & 1st follow up & $6.25 \pm 0.67$ & $0.034^{* *}$ \\
& 2nd follow up & $7.24 \pm 0.83$ & $0.020^{* *}$ \\
\hline
\end{tabular}

*Student $t$-test.

**Statistically significant 
Table 3. Health related quality of life scores using World Health Organisation-brief scale at JSS Hospital, Mysore, India in 2016.

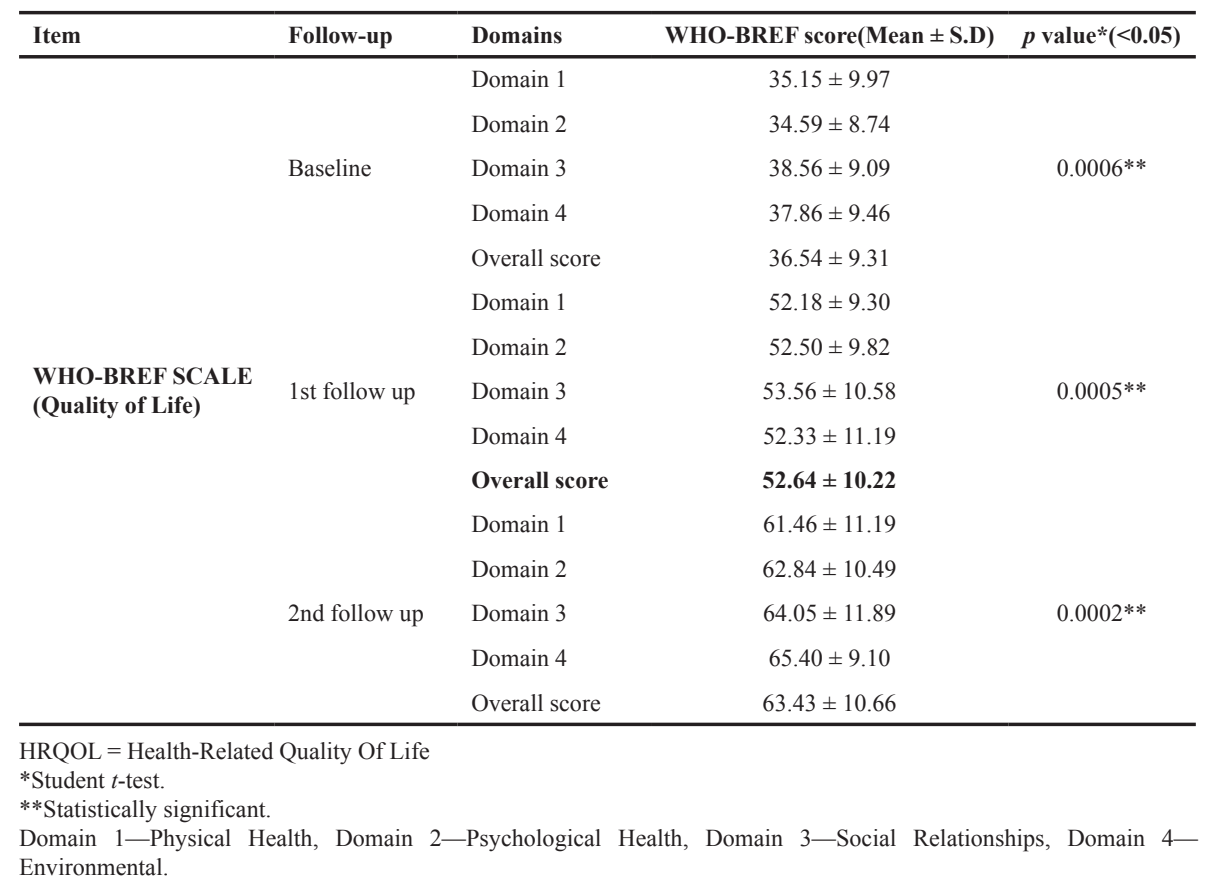

ensure the optimal use of available resources. As the need for the healthcare is increasing, patient-care is being provided by new models. One such model is collaborative-team care which means a beneficial interaction of two or more healthcare professionals, who put their unique skills and knowledge, to better assist patients and families with their health decisions. (Aronson et al., 2016). It employs the skills of the various healthcare professionals, such as pharmacists, who have potential in offering better outcomes related to medication adherence and quality of life of the patients (Fox and Reeves, 2015). In addition, collaborative patient education has the significant potential on the treatment satisfaction and selfmanagement (Rathert et al., 2013). The speciality like psychiatric pharmacy represents the aspects of pharmaceutical care of patients with psychiatric-related problems (Parthasarthi et al., 2004).

The demographic findings of this study are in contrast with the similar study conducted by Melo-Neto et al. (2008), where $65 \%$ were reported to be females. The study results have shown that the patient education provided by the pharmacist and psychiatrist are able to produce a statistically significant improvement in the adherence behavior of the patients toward prescribed medications using Medication Adherence Rating Scale. Similar findings were observed in another study where the intervention offered by the pharmacists yielded in an improvement in patient's mean medication adherence (OfforI Enato et al., 2011). Also, a statistically significant improvement in the quality of life of the patients was observed in all the follow-ups using WHOQOL-BREF scale. The degree of severity of psychiatric symptoms is one of the major elements that influence quality of life, coupled with social and personal functioning that plays a relevant role. Similar findings were reported in a study conducted by Galuppi et al. (2010), where patients have shown a reasonably good satisfaction concerning their quality of life.

Psychiatrists who involved in this study inferred that they need more support from pharmacists in the areas related to medication adherence and quality of life through counseling. Pharmacists want to participate in the areas which could use their specific knowledge and skills in appraising medication use, effectiveness, and tolerability (Maslen et al., 1996). All the patients should be evaluated for their quality of care that they receive irrespective of the nature of the psychiatric illness. Belief of psychiatrists that collaboration will result in enhanced medication adherence may strongly influence their likelihood of collaborating with the clinical pharmacists (Kelly et al., 2013, Nichols et al., 2002). Through further robust research and training, psychiatric pharmacy practice in India should be maintained to a level that is comparable to what is already obtained in the developed countries.

\section{CONCLUSION}

The pharmacist-psychiatrist collaborative patient education exhibits a significant improvement in patients' medication adherence and health-related quality of life. The clinical pharmacists in hospital setup play a vital role in patient education, medication adherence, and adverse reactions monitoring. The collaborative practice is rare in Indian setup, and this study is one among of its kind.

\section{LIMITATIONS}

As the study was conducted in only in one out-patient setting, the results cannot be generalizable to the entire psychiatric set ups in India.

\section{FUTURE DIRECTIONS}

This study shall be extended to in-patient settings to provide pharmacist-psychiatrist collaborative education to a larger patient groups, and it shall also be implemented in all other departments of the hospital in order to enhance the patient-related outcomes. 


\section{FUNDING}

None.

\section{CONFLICTS OF INTEREST}

There are no conflicts of interest declared.

\section{REFERENCES}

Aronson JK. "Collaborative care" is preferable to "patient centred care". BMJ, 2016; 353:i2926.

Chisholm-Burns M, Kim Lee J, Spivey C, Slack M, Herrier R, Hall-Lipsy E, Graff Zivin J, Abraham I, Palmer J, Martin JR, Kramer SS, Wunz T. US pharmacists' effect as team members on patient care. Med Care, 2010; 48(10):923-33.

Fox A, Reeves S. Inter-professional collaborative patient-centred care: a critical exploration of two related discourses. J Interprof Care, 2015; 29(2):113-8.

Galuppi A, Turola MC, Nanni MG, Mazzoni P, Grassi L. Schizophrenia and quality of life: how important are symptoms and functioning. Int J Ment Health Syst, 2010; 4(3):2-8.

Happell B, Manias E, Roper C. Wanting to be heard: mental health consumers' experiences of information about medication. Int J Ment Health Nurs, 2004; 13(4):242-8.

Kelly D, Bishop L, Young S, Hawboldt J, Phillips L, Keough T. Pharmacist and physician views on collaborative practice: Findings from the community pharmaceutical care project. Can Pharm J, 2013; 146(4):218-26.

Kucukarslan S, Lai S, Dong Y, Al-Bassam N, Kim K. Physician beliefs and attitudes toward collaboration with community pharmacists. Res Soc Admin Pharm, 2011; 7:224-32.

Maslen C, Rees L, Redfern P. Role of the community pharmacist in the care of patients with chronic schizophrenia in the community. Int J Pharm Pract, 1996; 4(4):187-95.

Melo-Neto VL, Valenca AM, Nascimento I, Lopes FL, Nardi AE. Quality of life assessment by WHOQOL-BREF in panic disorder patients during treatment. Rev Psiq Clín, 2008; 35(2):49-54.

Mishra A, Krishna GS, Alla S, Kurian TD, Kurian J, Ramesh M, Kishor M. Impact of pharmacist-psychiatrist collaborative patient education on medication adherence and quality of life (QOL) of bipolar affective disorder (BPAD) patients. Front Pharmacol, 2017; 8:722; doi:10.3389/ fphar.2017.00722

Mishra A, Krishna GS, Sravani A, Kurian TD, Kurian J, Ramesh M, Kishor M. Impact of pharmacist-led collaborative patient education on medication adherence and quality of life of schizophrenia patients in a tertiary care setting. Bull Fac Pharm Cairo Univ, 2017; 55(2):345-9.
Nichols J. Pharmacist scope of practice. Ann Intern Med, 2002; 136(4):W2.

OfforI Enato E. Patients' assessment of pharmacists' medication counseling in a psychiatric hospital in Nigeria. Trop J Pharm Res, 2011; 10(4):507-16.

Ormel J, Petukhova M, Chatterji S, Aguilar-Gaxiola S, Alonso J, Angermeyer M, Bromet EJ, Burger H, Demyttenaere K, de Girolamo G, Haro JM, Hwang I, Karam E, Kawakami N, Lépine JP, Medina-Mora ME, Posada-Villa J, Sampson N, Scott K, Ustün TB, Von Korff M, Williams DR, Zhang M, Kessler RC. Disability and treatment of specific mental and physical disorders across the world. Br J Psychiatr, 2008; 192(5):368-75.

Parthasarthi G, Karin N-H, Nahata MC. Clinical pharmacy in India. A textbook of clinical pharmacy practice, vol. 1. Universities Press, Hyderabad, India, pp 1-8, 2004.

Phokeo V, Sproule B, Raman-Wilms L. Community pharmacists attitudes toward and professional interactions with users of psychiatric medication. Int J Soc Psychiatr, 2004; 55(12):1434-6.

Rathert C, Wyrwich MD, Boren SA. Patient-centered care and outcomes: a systematic review of the literature. Med Care Res Rev, 2013 70(4):351-79.

Stoner S, Ott C, DiPaula B. Psychiatric pharmacy residency training. Am J Pharm Educ, 2010; 74(9):163.

Thakkar KB, Jain MM, Billa G, Joshi A, Khobragade AA. A drug utilization study of psychotropic drugs prescribed in the psychiatry outpatient department of a tertiary care hospital. J Clin Diagn Res, 2013; 7(12):2759-64

The WHOQOL Group. Development of the World Health Organization WHOQOL-BREF Quality of Life Assessment. Psychol Med, $1998 ; 28: 551 ; 8$

Thompson K, Kulkarni J, Sergejew AA. Reliability and validity of a new Medication Adherence Rating Scale (MARS) for the psychoses. Schizophr Res, 2000; 42:24100;

\section{How to cite this article:}

Gudi SK, Mishra A, Kurian TD, Alla S, Kurian J, Ramesh M, Kishor M. Initiation of pharmacist-psychiatrist collaborative patient education in ambulatory care settings of a tertiary care teaching hospital in south India. J Appl Pharm Sci, 2019; 9(07):078-081. 